\title{
Study of the behavior of a multistage dryer provided with downcomer
}

\author{
Verduzco Mora, L.A. ${ }^{a}$; Martínez Vera C. ${ }^{\text {; }}$, Vizcarra Mendoza, M.G. ${ }^{\text {a* }}$ \\ aUniversidad Autónoma Metropolitana - Iztapalapa, CDMX, México. \\ *E-mail of the corresponding author: $\underline{\text { mgvm@xanum.uam.mx }}$
}

\begin{abstract}
We study the behavior of a multi-stage fluidized bed dryer operated continuously with dowcomers. With the kinetics of silica gel drying depending on the mass of solids in the dryer and the gas feeding temperature, $E=14.5$ $\mathrm{KJ} / \mathrm{mol}$, and the distribution of residence times of solids through the dryer, modeling by $N$ tanks agitated in series, the experimental moisture content of the solids coming out of the dryer is compared with the predicted by the Vanecek model.
\end{abstract}

Keywords: fluidization; gel of sílice; continuous multistage dryer. 


\section{Introduction}

Drying is one of the most important operations in the chemical, metallurgical, pharmaceutical and food industry, among others, being the drying in fluidised beds, one of the most successful techniques in the drying of solids such as seeds, fertilizers, polymers, minerals and other important chemicals ${ }^{[1,2,3]}$.

In general, fluidised solids can be considered perfectly mixed, therefore, in a batch-operated dryer, a uniform treatment of the solids being dried is guaranteed; However, when the equipment is operated continuously, the solids that come out of the dryer present distribution of residence times and therefore different degrees of drying ${ }^{[4]}$. An option to overcome these disadvantages is the use of multi-stage fluidized bed columns ${ }^{[5]}$. By passing the solids through several stages connected in series, either in vertical or horizontal arrangement tends to reach a piston flow pattern, which is tantamount to narrowing the distribution of residence times. It can be stated therefore that as long as the flow of solids deviate from the perfect mixing and tent to the piston flow, the particle population coming out of the dryer will have a more uniform moisture content. In the operation of multi-stage fluidized bed columns with downcomers, one of the difficulties presented is to keep the flow of solids from stage to stage stable ${ }^{[4,6,7,8]}$ It has been established that the zone of stable operation of these equipment is function of the fluxes of solid and gas through the column, as well as of the employment or not of a reduction in the inferior cross-section of the downcomer. This considerably decreases the treatment capacity of the solids, which may represent a limitation for the application of this technology.

This research evaluates the influence of the number of stages, the relatiom between the length of the downcomer to diameter of the dryer (L/D) and the air supply temperature on the final moisture content in silica gel particles. The continuous operation is modelled through an integral type model derived from the equation proposed by Vanecek ${ }^{[9]}$.

\subsection{Mathematical model of continuous dryer}

The performance of a continuous fluidized bed dryer can be evaluated from the drying kinetics obtained experimentally in a batch dryer and by the use of the corresponding function of the residence time distribution of solids $(\mathrm{E}(\mathrm{t}))$ in the continuous operation of the dryer. This is expressed mathematically by Eq. (1) ${ }^{[9]}$.

\subsubsection{Drying kinetics}

$$
X_{e}=\int_{0}^{\infty} X(t) E(t) d \tau
$$

Considering that the drying kinetics of silica gel can be represented by an exponential model similar to Newton's second law of cooling, the following expression is proposed, Eq. (2): 


$$
-\frac{\mathrm{dX}}{\mathrm{dt}}=\mathrm{kX}
$$

This expression is integrated, considering that at $\mathrm{t}=0, X=\mathrm{X}_{0}$, thus obtaining Eq. (3)

$$
\mathrm{X}=\mathrm{X}_{0} \times \operatorname{EXP}(-\mathrm{kt})
$$

where $\mathrm{k}$, is a coefficient that considers the effects of the air supply temperature, according to an Arrhenius type equation and that is represented by the following relationship:

$$
\mathrm{k}=\mathrm{A} \times \operatorname{EXP}\left(-\frac{\mathrm{E}}{\mathrm{RT}}\right)
$$

Where, $\mathrm{A}$ is the preexponential factor, $\mathrm{E}$ the activation energy and $\mathrm{R}$ the universal constant of the gases. Substituting Eq. (4) in Eq. (3), the drying kinetics is obtained as a function of temperature and time, Eq. (5):

$$
\mathrm{X}=\mathrm{X}_{\mathrm{o}} \times \operatorname{EXP}[-\mathrm{A} \times \operatorname{EXP}(-\mathrm{E} / \mathrm{RT}) \mathrm{t}]
$$

\subsection{2. $\quad$ Resident Time Distribution (RTD)}

To establish the residence time distribution function of the solids $(\mathrm{E}(\mathrm{t}))$ that go through the multi-stage dryer, the series of stirred tanks model ${ }^{[10]}$ was used.

Thus the DTR as a function of time is given by Eq. (6), for $\mathrm{N}$ geometrically identical stages ${ }^{[2]}$

$$
E(t)=\frac{1}{\tau_{i}}\left(\frac{t}{\tau_{i}}\right)^{N-1} \times \frac{1}{(N-1) !} * e^{-t / \tau_{i}}
$$

Where $\tau_{\mathrm{i}}$ is the residence time of the solids in stage $\mathrm{i}$.

\subsubsection{Moisture content of the solids at the exit of the multi-stage dryer.}

Finally, substituting the equations (5) and (6) in (1), we obtain the equation for the calculation of the moisture content of the solids at the exit of the multistage dryer as a function of the temperature and the number of stages:

$$
\mathrm{X}_{\mathrm{e}}=\int_{0}^{\infty}\left\{\left[\mathrm{X}_{\mathrm{o}} * \operatorname{EXP}[-\mathrm{A} \times \operatorname{EXP}(-\mathrm{E} / \mathrm{RT}) \mathrm{t}]\right] \times\left[\frac{1}{\tau_{\mathrm{i}}}\left(\frac{\mathrm{t}}{\tau_{\mathrm{i}}}\right)^{\mathrm{N}-1} \times \frac{\exp \left(-\frac{\mathrm{t}}{\tau_{\mathrm{i}}}\right)}{(\mathrm{N}-1) !}\right]\right\} \mathrm{dt}
$$

\section{Materials and Methods}

\subsection{Materials}

Silica gel was used: $d_{p}=1.8 \times 10-3 \mathrm{~m}, \rho_{\mathrm{p}}=2.1 \times 10^{3} \mathrm{Kg} / \mathrm{m}^{3}, \varepsilon_{\mathrm{mf}}=0.67, \varphi=1, \mathrm{U}_{\mathrm{mf}}=1.4$ $\mathrm{m} / \mathrm{s}$, solid type $\mathrm{D}$ of the Geldart classification. 


\subsection{Methods}

\subsubsection{Experimental Dryer}

Fig. 1 shows the equipment used in this study and that served to perform the hydrodynamic study of the column, stable operation and distribution of residence times of the solids, the kinetics of drying of the silica gel and the continuous operation of the multistage dryer.

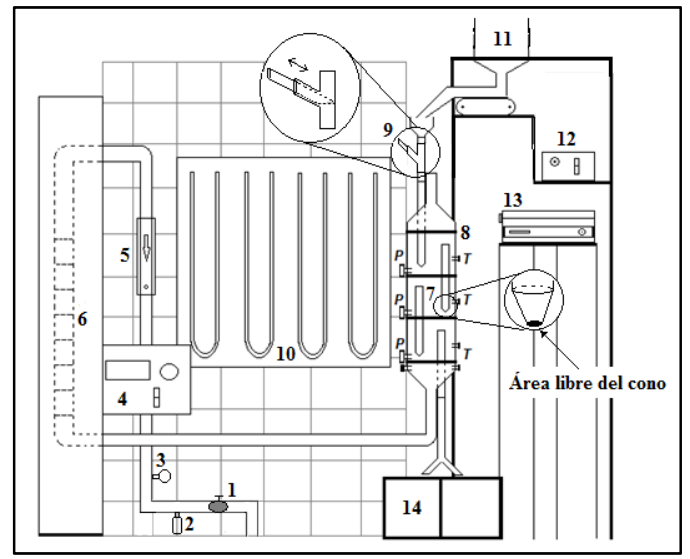

Fig. 1. Multi-stage dryer. 1.- Valve, 2.- Humidity trap, 3.- Pressure regulator, 4.- Feed air temperature control, 5.-Rotameter, 6.- Electric resistance heater, 7.- Downcomers, 8 .- Multi-stage Column (0.095 m ID $\times 0.25 \mathrm{~m}$ height, each stage), 9.-Valve for tracer injection, 10.- Manometers in $U$, 11.- Feeder of solids, 12.- Control of the feeder of solids, 13.- Temperature recorder, 14.- Collector of solids P.- Points to measure pressure drops, T.- Ports for temperature measurement.

\subsubsection{Drying Kinetics}

The fluid bed dryer operated in batch with a single stage, is thermally stabilized at one of the previously established temperatures (T), 50, 60 or $70{ }^{\circ} \mathrm{C}$ and one of the loads of solids in the dryer $\left(\mathrm{W}_{\mathrm{i}}\right), 0.360,0.720$ or $1.080 \mathrm{Kg}$ of gel of silica, corresponding to the height $(\mathrm{L})$ to bed diameter (D) ratio of $0.5,1.0$ and 1.5 , respectively. The air velocity remained constant at 2.24 $\mathrm{m} / \mathrm{s}$ (1.6 Umf). During each experimental run, samples of approximately $2.0 \times 10^{-3} \mathrm{Kg}$ are taken and stored hermetically to later determine their moisture content. At the same time the temperatures in the bed are monitored. This routine is repeated for all temperatures and solids loads contemplated in the experimental domain.

\subsubsection{Residence Time Distribution of solids}

The "pulse" type of stimulus-response technique was used. Once the dryer operates continuously and in a steady state, an amount of tracer (silica gel with blue indicator) is "injected" into the feed stream (approximately $0.025 \mathrm{Kg}$ ), once this is done the valve is opened again so that the fresh solid continues to feed continuously. When the tracer enters the bed, the time starts to be taken and from this point samples of the concentration of tracer 
are taken at the exit of the column in 30 seconds lapses. The function of RTD is obtained from the methodology reported by Levenspiel ${ }^{[2]}$. The tracer injection is done quickly enough to avoid that the downcomer is left without solids and thus avoid a possible destabilization in the column.

\section{Results and discussion}

From a previous study, the stable operation area of the multistage column was determined by operating the downcomers with a conical reduction, in its lower part equivalent to $45 \%$ of free area ${ }^{[1]}$. In this way, the solid and air fluxes were fixed respectively, in $5.3 \times 10-4 \mathrm{Kg}_{\mathrm{ds}} /$ $\mathrm{s}$ and $5.2 \times 10-3 \mathrm{Kg}_{\mathrm{dg}} / \mathrm{s}$, which remain constant during the experiments.

\subsection{Drying Kinetics}

In Fig. 2 are shown the moisture profiles in the solid as it dries for the different air feed temperatures to the dryer. It can be seen that the constant drying period ranges from $\mathrm{X}_{\mathrm{o}}=$ $0.37 \mathrm{KgH}_{2} \mathrm{O} / \mathrm{Kg}_{\mathrm{ds}}$ to a critical point that oscillates between 0.15 and $0.20 \mathrm{KgH}_{2} \mathrm{O} / \mathrm{Kg}_{\mathrm{ds}}$. It is observed that all the curves present period of constant drying speed and that as the load of solids in the dryer increases, the temperature of the bed takes longer to reach the air inlet temperature. In the same way, the higher the load of solids in the bed, the drying is slower, because there is more moisture to remove for a constant flow of air.
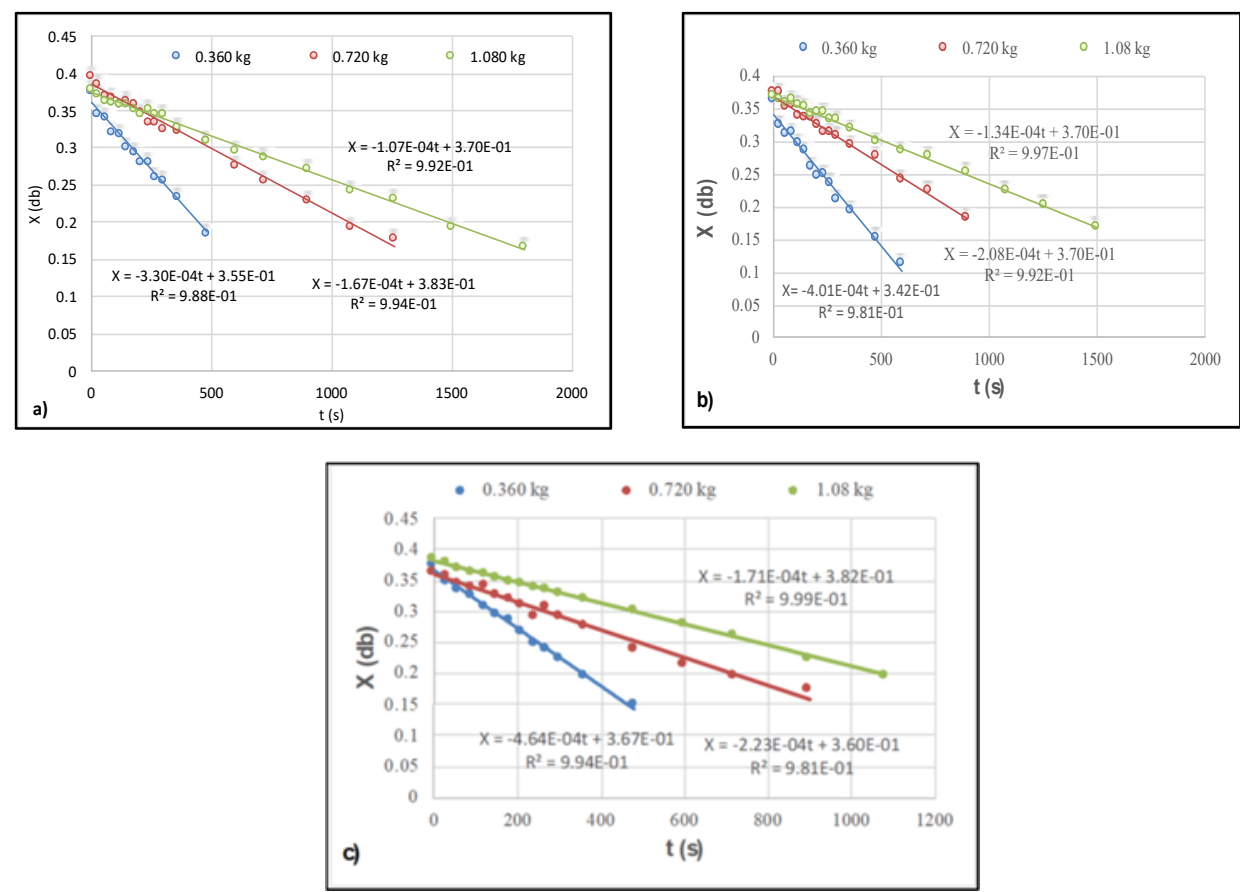

Fig. 2.- Drying kinetics of the silica gel in the period of constant drying as a function of the charge of solids in the dryer. a) $50^{\circ} \mathrm{C}$; b) $60^{\circ} \mathrm{C}$; c) $70^{\circ} \mathrm{C}$ 
When plotting the linearized form of Eq. 3, applied to the constant drying period, we obtain the value of the constant $\mathrm{k}$, which is presented in table 1 for the different experimental conditions.

Table 1.- Values of the silica gel drying constant

\begin{tabular}{ccccc}
\hline $\mathrm{T}\left({ }^{\circ} \mathrm{K}\right)$ & $\mathrm{W}(\mathrm{kg})$ & $\mathrm{k} \times 10^{3}\left(\mathrm{~s}^{-1}\right)$ & $\mathrm{E}(\mathrm{KJ} / \mathrm{mol})$ & $\mathrm{A}\left(\mathrm{s}^{-1}\right)$ \\
\hline 323 & 0.36 & 1.330 & & \\
333 & 0.36 & 1.720 & 14.78 & 0.337 \\
343 & 0.36 & 1.830 & & \\
323 & 0.72 & 0.622 & & 0.135 \\
333 & 0.72 & 0.758 & 14.42 & \\
343 & 0.72 & 0.850 & & 0.096 \\
323 & 1.08 & 0.434 & & \\
333 & 1.08 & 0.500 & 14.51 & \\
343 & 1.08 & 0.595 & & \\
\hline
\end{tabular}

It can be seen that practically the loading of solids in the dryer does not appreciably affect the value of the activation energy, however this parameter affects the value of the preexponential factor, as can be seen in Fig. 3.

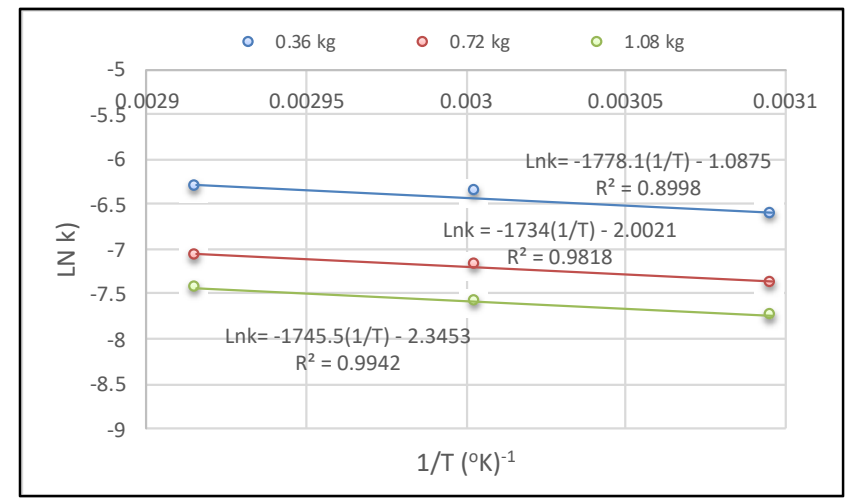

Figure 3.- Activation Energy and Pre-exponential Factor.

\subsection{Residence Time Distribution}

The table 2 shows the values corresponding to the residence time that the solids remain in a stage at the different $\mathrm{L} / \mathrm{D}$ ratios. 
Table 2. RTD of the solids in the multi-stage fluidized bed dryer

\begin{tabular}{ccc}
\hline $\mathrm{L} / \mathrm{D}$ & $\mathrm{W}(\mathrm{kg})$ & $\tau(\mathrm{s})$ \\
\hline 0.5 & 0.120 & 226 \\
1.0 & 0.240 & 453 \\
1.5 & 0.360 & 680 \\
\hline
\end{tabular}

\subsection{Continuous operation of the multistage dryer.}

For $\mathrm{N}=3, \tau_{\mathrm{i}}=680 \mathrm{~s},(\mathrm{~L} / \mathrm{D})_{\mathrm{i}}=1.5(0.360 \mathrm{Kg})$, Eq. (7) left:

$\mathrm{X}_{\mathrm{e}}=\frac{\mathrm{X}_{\mathrm{o}}}{2 \tau_{\mathrm{i}}^{3}} \int_{0}^{\infty}\left[\mathrm{t}^{2} \operatorname{EXP}-\left(\left(0.096 * \operatorname{EXP}\left(-\frac{1750}{\mathrm{~T}}\right)+\frac{1}{\tau_{\mathrm{i}}}\right) \mathrm{t}\right] \mathrm{dt}\right.$

The results obtained by comparing the experimental humidity of the output of the dryer solids with those calculated with the Eq. (7) are presented in Fig. 4

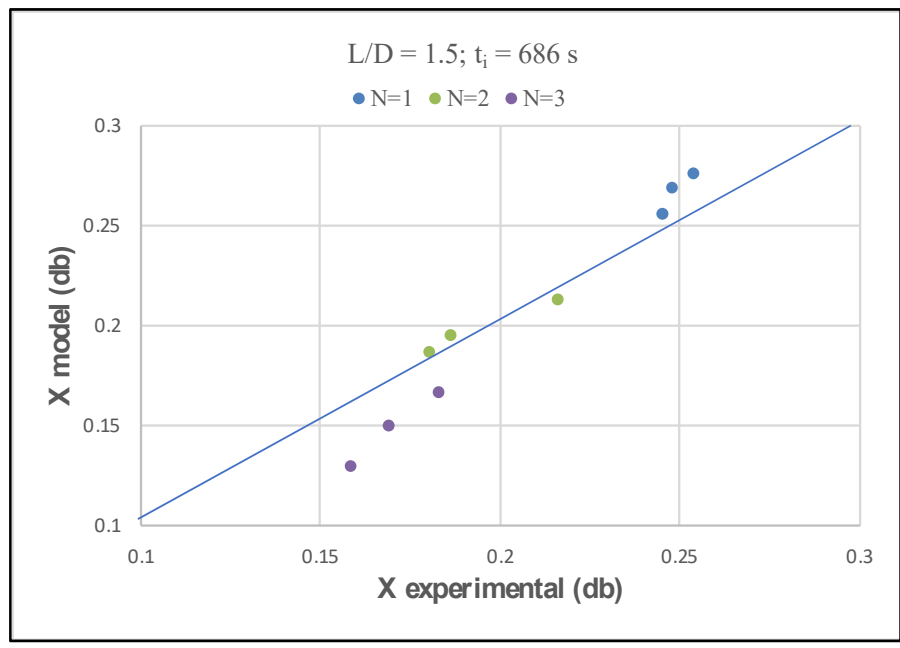

Fig. 4 Prediction of moisture content at the dryer outlet at different temperaturas

\section{Conclusion}

In this paper we show that the equation proposed by Vanecek, 1966, reasonably well predicts the humidity of the solids that come out of a multistage dryer.

It was found that the activation energy related to the drying process is independent of the load of solids in the dryer, but not for the pre-exponential factor.

Finally, it was found that the drying kinetics can be reasonably well represented by a first order power law model 


\section{References}

[1] Srinivasa C., Thomas P. P., Varma Y. B. G., Drying of Solids in Fluidized Beds. Ind. Eng. Chem. Res. 1995, 34, 3068-3077.

[2] Kunii D., Levenspiel O. Fluidization Engineering; Ed. Butterworth-Heinemann1991.

[3] Zahed A. H., Epstein N., Batch and Continuous Spouted Bed Drying of Cereal Grains. The Thermal Equilibrium Model. The Canadian J. of Chem. Eng. 1992, 70, 945-953.

[4] Martín I. G., Marcilla A., Font R. y Asensio M. Stable Operating Velocity Range for Multistage Fluidized Bed Reactor with Downcomers, Powder Techn.1995, 85,193-201.

[5] Srinivasa C., Subramanian N. B. Some Drying Aspects of Multistage Fluidized. Beds, Chem. Eng. Tecnol. 1998, 21, 961-966.

[6] Mohanty C. R., Rajmohan B., Meikap B. C. Identification of stable operating ranges of a counter current multistage fluidized bed reactor with downcomer. Chemical Engineering and Processing: Process Intensification 2010, 49, 104-112.

[7] Mohanty C.R., Adapala S., Meikap B.C. Hold-up Characteristics of a Novel gas-solid Multistage Fluidized Bed Reactor for Control of Hazardous Gaseous Effluents. Chem. Eng. Journal 2009, 148, 115-121.

[8] Santiago T., Anaya I., Alamilla L., Chanona J. J., Gutierrrez G. F., Vizcarra M.G., Hydrodynamics and Operational Parameters of a Continuous Multistage Vertical Fluidized Bed System, Revista Mexicana de Ingeniería Química 2007, 6 59-63.

[9] Vanecek V., Markvart M., Drbohlav R., Fluidized Bed Drying; Leonard Hill, London, 1966.

[10] Verduzco-Mora, L.A., Martínez-Vera, C., Vizcarra-Mendoza, M.G. Hidrodinámica de un secador multietapas de lecho fluidizado continuo con vertederos. Revista Mexicana de Ingeniería Química 2015, 14(2), 467-479 